\title{
Por que o duplo caráter do trabalho é o "ponto crucial em torno do qual gira a compreensão da Economia Política"?
}

João Machado Borges Neto

\begin{abstract}
Resumo: Este artigo procura explicar por que Marx afirmou que o duplo caráter do trabalho que produz mercadorias é "o resultado crítico final de mais de século e meio de pesquisas da Economia Política clássica", "o ponto crucial em torno do qual gira a compreensão da Economia Política”, e ainda "o segredo de toda a concepção crítica", questão à qual não se costuma dar a importância devida. Ao mesmo tempo, o artigo procura avaliar se esta ênfase de Marx é justificada, e conclui afirmativamente: o duplo caráter do trabalho é decisivo para a compreensão do dinheiro, do capital, dos efeitos contraditórios do progresso técnico, e de toda a dinâmica contraditória da economia capitalista.
\end{abstract}

Palavras-chave: Economia política; valor; duplo caráter do trabalho.

\section{Why the twofold nature of labor is the crucial point to an understanding of Political Economy?}

\begin{abstract}
This paper tries to explain why Marx has written that the twofold nature of labor that produces commodities is "the final critical result of more than a century and a half of research of Classical Political Economy", a "point [that] is crucial to an understanding of political economy", and yet "the secret of the whole critical conception", question that has not been stressed as it deserves. At the same time the paper tries to evaluate if this emphasis is correct, and it

1 Professor do Departamento de Economia e do Programa de Estudos Pós-Graduados de Economia Política da PUC-SP. E-mail: jmborges@pucsp.br
\end{abstract}


BORGES NETO, J. Por que o duplo caráter do trabalho é o ...

concludes affirmatively: the twofold nature of labor is central to understanding money, capital, the contradictory effects of technical progress, and the whole contradictory dynamics of capitalist economy.

Keywords: Political Economy; value; twofold nature of labor.

JEL: A10；B14；B51

Introdução

Marx afirmou repetidamente que a questão do duplo caráter do trabalho que produz mercadorias é a questão central para a compreensão da Economia Política e para sua crítica.

Em Para a Crítica da Economia Polí-tica, após a exposição do tema do trabalho abstrato na primeira parte do Capítulo I, "A merca-doria", o anexo deste capítulo, "Apontamentos históricos para a análise da mer-cadoria”, começa dizendo que

A análise da mercadoria através da redução desta a um trabalho de dupla forma (de um lado, a redução) do valor de uso a um trabalho real, isto é, à atividade produtiva aplicada a um fim, de outro, do valor de troca a tempo de trabalho, ou seja, a trabalho social igual, é o resultado crítico final de mais de século e meio de pesquisas da Economia Política clássica. [Para a Crítica da Economia Política:47]²

A seqüência do texto ressalta a importância desta distinção entre o "trabalho real, atividade produtiva aplicada a um fim" e "trabalho social igual”.

O Capítulo I do Livro I de O Capital voltou a enfatizar este ponto, explicitando mais claramente que a questão-chave é "a natureza dupla do trabalho contido na mercadoria” (e não a dupla natureza da própria mercadoria):

Essa natureza dupla do trabalho contido na mercadoria foi criticamente demonstrada pela primeira vez por mim. Como esse é o ponto crucial em torno do qual gira a compreensão da Economia Política, ele deve ser examinado mais de perto. [O Capital I-I:49; El Capital I-I:51] ${ }^{3}$

2 Nas citações de textos de Marx, no lugar de adotar o procedimento habitual de fazer referência ao ano da publicação, foi mencionado o título da obra. Nas citações de $O$ Capital foi tomado como base o texto da edição brasileira da Nova Cultural, cotejado com o texto da edição da Siglo Veintiuno Editores, cuja tradução é mais cuidadosa.

3 Como havia um salto na tradução brasileira, ela foi completada com base na edição da Siglo Veintiuno Editores. 
Em uma carta a Engels, escrita na época da publicação da primeira edição do Livro I de $O$ Capital, Marx foi igualmente enfático:

(...) [O] que há de melhor no meu livro é: 1- (e é sobre isto que repousa toda a inteligência dos fatos) o destaque, desde o primeiro capítulo, do caráter duplo do trabalho, conforme ele se expressa em valor de uso ou em valor de troca; 2 a análise da mais-valia, independentemente de suas formas particulares..."). [Marx a Engels, 24/08/1867; Marx \& Engels 1964:174]

Em outra carta a Engels, disse que "este [o duplo caráter do trabalho representado na mercadoria] é de fato o segredo de toda a concepção crítica":

Uma coisa bem simples escapou a todos os economistas sem exceção, é que se a mercado-ria tem um duplo caráter de valor de uso e de valor de troca, é necessário que o trabalho re-presentado nesta mercadoria possua este duplo caráter ele também; enquanto que a mera análise do trabalho sans phrase, tal como a encontramos em Smith, Ricardo, etc., se choca por toda parte fatalmente com problemas inexplicáveis. É este de fato todo o segredo da concepção crítica. [Marx a Engels, 08/ 01/1868; Marx \& Engels 1964:195]

Também em seu último escrito sobre O Capital - as Notas sobre Wagner - Marx voltou a enfatizar o duplo caráter do trabalho:

Por outro lado, o vir obscuros não se deu conta de que, já ao fazer a análise da mercadoria, eu não me detenho na dupla modalidade sob a qual se apresenta, mas passo imediatamente a demonstrar que nesta dupla modalidade da mercadoria se manifesta o duplo caráter do trabalho de que aquela é produto; do trabalho útil, isto é, dos modi concretos dos distintos trabalhos que criam valores de uso e do trabalho abstrato, do trabalho como gasto de força de trabalho, qualquer que seja o modo "útil" como se gaste (...) [Notas sobre Wagner:50]

Seria difícil dar maior importância a esta questão do que Marx fez nestas pas-sagens: para ele, ela "é o resultado crítico final de mais de século e meio de pesquisas da Economia Política clássica", "o ponto crucial em torno do qual gira a compreensão da Economia Política", e ainda "o segredo de toda a concepção crítica”! No entanto, ele próprio não a explicitou sempre ao longo de $O$ Capital, como seria de se esperar ${ }^{4}$, embora sem dúvida ela esteja presente ao longo de todo o livro. Além disso, as interpreta-ções posteriores da teoria econômica de Marx quase sempre não lhe dão um lugar central; a outra questão citada por ele 
na carta a Engels como contribuição fundamental sua - a análise da mais-valia em geral antes das suas formas particulares - tem sua importância muito mais lembrada, embora ele a tivesse colocado em segundo lugar.

O tratamento do conceito de trabalho abstrato e da forma do valor, tal como foi feito por Isaac Rubin nas primeiras décadas do século XX [Rubin 1980 e 1994; trabalhos originalmente publicados em russo, em 1928 e 1927], e retomado por diversos economistas, muitos dos quais se inspiraram na obra deste autor, a partir dos anos 1970, deve ser considerado uma maneira de enfatizar a importância do duplo caráter do trabalho. Mas o conceito de trabalho abstrato não chama a atenção para alguns dos aspectos mais importantes do duplo caráter do trabalho, relacionados com a interação contraditória das duas naturezas do trabalho (como desenvolveremos adiante).

Apenas alguns autores colocam o duplo caráter do trabalho que produz mercadorias de forma explícita no centro de sua interpretação. Um deles é Henrik Grossmann, em Marx, l'Economie Politique Classique et le Problème de la Dynamique [Grossmann 1975; edição original em alemão de 1940]. Se-guindo os comentários de Marx citados, ele afirma (e fundamenta) que esta questão tem o lugar central na distinção entre a economia marxista e a Econo-mia Política Clássica. Outro autor que lhe atribui uma importância primordial é Moishe Postone [Postone 1978 e Postone 1993]; para ele, uma das debilidades mais importantes do que chama de "marxismo tradicional" é justamente desprezá-la, e a partir daí tratar o traba-lho como uma categoria trans-histórica.

Podemos lembrar também autores que privilegiam a discussão da forma do valor e que enfatizam, neste contexto, a importância do duplo caráter do trabalho. Assim, Jean Cartelier, na conclusão de Excedente y Reproducción [1981; edição original em francês, de 1976], "Marx y la crítica de la economia polí-tica”, destaca a importância do duplo caráter do trabalho na distinção entre a economia de Marx e a Econo-mia Política Clássica. Mas sua interpretação althusseriana parece particularmente desfavorável para a extra-ção das conseqüências mais interessantes desta ênfase; e o pensamento de Cartelier, depois deste livro, evo-luiu em outra direção. Também Geert Reuten e Michael Williams se referem ao duplo caráter do trabalho [Reuten \& Williams 1989, Reuten 1995:105-6 especialmente].

Mesmos estes autores, no entanto, não procuraram explicar qual é a razão para que este seja "o ponto crucial em torno do qual gira a compreensão da Economia Política”. Justifica-se, portanto, um exame mais detido deste tema. 


\section{O "trabalho humano abstrato"}

Há uma maneira trivial de entender o conceito de trabalho abstrato, para a partir daí justificar a importância do duplo caráter do trabalho: lembrar que o trabalho que produz as dis-tintas mercadorias, para ser comparado quantitativamente, tem de ser tomado como homo-gêneo, igual. Este entendimento certamente não justificaria toda a importância atribuída por Marx ao tema; além do mais, não pode haver muita dúvida de que os antecessores de Marx, em particular Ricardo, pensavam no trabalho humano como uma coisa homogênea, e é por isso que não viam problemas em quantificá-lo e compará-lo.

De fato, a originalidade de Marx começa precisamente na direção oposta - a de problematizar o caráter homogêneo do trabalho. Já no Capítulo I do Livro I, após con-cluir que o valor, o "algo comum" que os valores de troca exprimem, só pode vir da abs-tração dos valores de uso, e passar então à análise do trabalho, Marx constata que também o caráter material, concreto, do trabalho deve ser abstraído para que cheguemos a "igual trabalho humano", a "trabalho humano abstrato" [O Capital I-I:46-7; El Capital I-I:46-7]. Esta problematização do caráter homogêneo do trabalho leva, portanto, à explicitação do conceito de trabalho abstrato como "igual trabalho humano", trabalho do qual é abstraído seu caráter material, concreto, útil, de "atividade produtiva aplicada a um fim" específico.

Quando chegamos a este conceito tendo percorrido este caminho, duas questões fundamentais se destacam. A primeira refere-se ao fato de a "abstração" que conduz do trabalho concreto (ou, melhor dizendo, das diversas formas de trabalho concreto) ao trabalho abstrato não ser apenas uma abstração mental, mas sim uma abstração que se realiza na própria realidade. Se o "trabalho abstrato" fosse apenas uma abstração mental, não teria "densidade" social para constituir a "substância do valor", ou seja, o valor seria reduzido a uma mera construção mental. Justamente por isso o conceito de trabalho abstrato está longe de ser uma maneira trivial de dizer que o trabalho dos diversos indivíduos por ser tomado como homogêneo. Este ponto tem sido comentado (por exemplo, em Colletti 1974 ou Fausto 1983; Isaak Rubin deve ser considerado o pioneiro desta interpretação), mas em geral não são retiradas dele todas as implicações importantes. Voltaremos a ele em seguida.

A segunda questão consiste num desdobramento desta: a existência do caráter igual, abstrato, do trabalho é um resultado histórico. Este caráter histórico do trabalho abstrato (que só se realiza plenamente na economia capitalista já desenvolvida) tem sido enfatizado por vários autores (como os citados no parágrafo anterior), a partir de observações do 
próprio Marx. Voltaremos adiante a este ponto; aqui, cabe discutir em maior detalhe a primeira questão, enfatizada acima.

Para que o trabalho abstrato possa se constituir na substância do valor, sem que o valor se torne uma mera construção mental, ele tem de ser algo real. Este ponto fica mais claro quando o trabalho (abstrato) é contraposto ao outro fundamento para o valor proposto pelos economistas, a utilidade. Logo no início do Capítulo I do Livro I de O Capital, Marx mostrou por que qualquer aspecto do valor de uso (o que inclui, naturalmente, a utilidade) não pode ser o fundamento do valor. Após concluir que "o valor de troca só pode ser o modo de expressão, a 'forma de manifestação' de um conteúdo dele distinguível" [O Capital I-I: 46; El Capital: I-I: 45], Marx se pergunta o que pode ser este conteúdo comum. Constata então que ele

(...) não pode ser uma propriedade geométrica, física, química ou qualquer outra proprie-dade natural das mercadorias. (...) propriedades corpóreas [das mercadorias] só entram em consideração à medida que elas lhes conferem utilidade, isto é, tornam-nas valores de uso. Por outro lado, porém, salta à vista que é precisamente a abstração de seus valores de uso que caracteriza a relação de troca das mercadorias. Dentro da mesma um valor de uso vale exatamente tanto quanto outro qualquer, desde que esteja disponível em proporção adequada. (...) Como valores de uso, as mercadorias são, antes de mais nada, de diferente qualidade, como valo-res de troca só podem ser de quantidade diferente, não contendo, portanto, nenhum átomo de valor de uso. [O Capital I-I: 46-7; El Capital: I-I: 46]

A afirmação central deste parágrafo é: "salta à vista que é precisamente a abstra-ção de seus valores de uso que caracteriza a relação de troca das mercadorias". A rela-ção de troca nega os valores de uso. Assim, para encontrar o que há de comum nas merca-dorias enquanto valores de troca, temos de deixar de lado seus valores de uso, e com eles todas as suas propriedades naturais. ${ }^{5}$

Ou seja, Marx argumentou que a utilidade em geral somente pode ser uma generalização mental sem existência própria - a utilidade existe apenas nos va-lores de uso singulares, e esta é uma razão de fundo para rejeitá-la como possível funda-mento do valor. De modo mais geral, o

5 Observemos que, para excluir a utilidade, ao lado de todas as propriedades naturais, como possível conte-údo comum, este raciocínio se apóia implicitamente no argumento desenvolvido antes, de que não existe uma "utilidade em geral", a não ser como abstração de gênero. Se existisse uma "utilidade em geral", ela poderia servir de base para a troca. Apenas a partir daí poderia ser examinado se, de fato, as mercadorias se trocam em proporções em que suas utilidades são igualadas; e poder-se-ia chegar ao artifício da "utilidade marginal". A objeção de Marx contra a explicação do valor a partir da utilidade é muito mais pro-funda do que o chamado "paradoxo da água e do diamante". 
mesmo argumento leva à rejeição de todos os aspectos incluídos no conceito de valor de uso). Ele não afastou a utilidade em geral como possível fundamento do valor com base em argumentos puramente lógi- $\cos ^{6}$, mas por ela não ter existência real [Kay 1979:52-4]. Trata-se, portanto, de um ar-gumento que tem também uma base empírica, que podemos exemplificar da seguinte maneira: é impossível usar ali-mentos sólidos para matar a sede; no meio de um deserto, não há quantidade de alimentos sólidos que possa substituir a água. Se houvesse uma utilidade em geral, de modo que as utilidades particulares se distinguissem apenas por sua quantidade, isto seria possível. Por outro lado, como valores ${ }^{7}$, alimentos podem substituir a água - ser trocados por ela. ${ }^{8}$

É possível explicar este caráter comum dos valores pelo trabalho e, portanto, argumentar que o trabalho em geral tem realidade? Segundo Marx, sim, é possível: pelo trabalho abstrato, que tem realidade como generalidade numa economia mercantil desenvolvida, ou seja, na economia capitalista [Fausto 1983].

\section{A dualidade das categorias da economia capitalista}

A partir da identificação do duplo caráter do trabalho, Marx construiu seu sistema teórico em torno de categorias econômicas duais: trabalho concreto e trabalho abstrato, valor de uso e valor, riqueza material (real) e riqueza abstrata (em valor), processo material de produção e processo de valorização, etc. A dualidade das categorias ocupa um lugar central na estrutura teórica de $O$ Capital.

A questão em discussão pode então ser posta da seguinte maneira: por que Marx destacou como ponto decisivo duplo caráter do trabalho, e não o duplo caráter da mercadoria, que foi como esta dualidade apareceu pela primeira vez? O duplo caráter da mercadoria, isto é, a contraposição entre valor de uso e valor (de troca), já era conhecido pela Economia Polí-tica clássica. O que foi acrescentado quando o duplo caráter do trabalho que produz mercadorias foi assinalado?

6 Posição que lhe foi atribuída por Böhm-Bawerk [1974; trabalho publicado originalmente em alemão, em 1896], entre outros.

$7 \mathrm{O}$ que supõe, naturalmente, que se trate de bens produzidos como mercadorias - a própria água não pode ser, então, um "bem livre".

8 A idéia de que as utilidades dos diversos bens podem ser tratadas como expressões de uma suposta "utilidade em geral" corresponde ao "axioma da substituição bruta", que diz que "tudo é substituível por qualquer coisa", afirmação manifestamente irrealista. Economistas pós-keynesianos, como Paul Davidson (por exemplo, em Davidson 1994:17) fazem da contestação deste axioma um dos eixos de sua crítica à economia neoclássica. 
Uma primeira explicação é bastante clara: sem o duplo caráter do trabalho, o duplo caráter da mercadoria fica um tanto esvaziado, torna-se quase trivial ${ }^{9}$; a distinção trabalho concreto $x$ trabalho abstrato permite completar e dar coerência à distinção valor de uso $x$ valor. Mais significativo ainda, com a descoberta do duplo caráter do trabalho Marx vai à fonte do duplo caráter da mercadoria. A citação de Para a Crítica da Economia Política feita acima introduz o tema desta maneira: tratase de analisar o duplo caráter da mercadoria por meio "da redução desta a um trabalho de dupla forma".

Assim, no Capítulo I do Livro I de O Capital, Marx deixa claro que a existência do valor (em contraposição ao valor de uso) se explica pelas peculiaridades do caráter social do trabalho na economia capitalista, que exigem que ele "receba uma objetividade de valor socialmente igual, separada de seu valor de uso, fisicamente diferenciada" (O Capital I-I: 71; El Capital I-I:89), o que acontece a partir do momento em que a mercadoria é produzida para venda. A existência do valor associa-se ao desenvolvimento do caráter abstrato do trabalho, à duplicação do trabalho.

Além disto, a afirmação da dupla natureza assumida pelo trabalho quando produz mercadorias permite fundar igualmente a contraposição entre riqueza material e riqueza capitalista, entre produção de valores de uso e produção de valor. Esta última não pode ser tratada a partir apenas do duplo caráter da mercadoria, e o mesmo acontece com a duplicidade de outras categorias econômicas. O ponto de partida de todas as dualidades é a contraposição entre a "atividade produtiva aplicada a um fim” específico e o gasto de tempo de trabalho genérico, social.

Em resumo: é a afirmação do duplo caráter do trabalho produtor de mercadorias que permite passar de uma questão quase trivial (o duplo caráter da mercadoria) para um sistema teórico que explica este duplo caráter e é construído a partir da dualidade geral das categorias econômicas.

Isto nos leva diretamente a outra questão fundamental: a dualidade do trabalho na economia capitalista consiste na distinção entre, de um lado, o trabalho enquanto atividade concreta e útil, existente em todas as formas de sociedade e, de outro, o caráter social específico e as funções que o trabalho assume na economia mercantil-capitalista, o que se des-dobra na distinção entre características técnicas e forma social do

9 A qualificação "quase" é necessária. Embora esta dualidade fosse muito clara para a Economia Política clássica, e possamos entender que ela pertence praticamente ao senso comum - uma coisa é o interesse que podemos ter em um produto se queremos consumi-lo, outra coisa é o interesse se queremos vendê-lo -, a economia neoclássica se assenta, entre outros aspectos, na sua negação (ou na desconsideração desta questão); a base da sua teoria do valor são justamente as utilidades dos "bens". 
trabalho. Assim, as necessidades do processo de produção capitalista desdobram-se em necessidades técnicas e necessidades ligadas especificamente à forma capitalista. Daí passamos ao duplo caráter do processo de gestão no capitalismo: ele tem um aspecto de coordenação, necessário dado o caráter coletivo do trabalho, que decorre, portanto, de necessidades técnicas do processo de produção, e um aspecto ligado às necessidades de valorização, próprio ao modo capitalista de produção. ${ }^{10}$

É a partir do caráter social específico do trabalho na economia mercantil-capitalista que se desenvolvem o fetichismo da mercadoria e seus derivados, que a economia capita-lista se distingue como uma forma social historicamente definida e as suas categorias como historicamente peculiares. ${ }^{11}$ Além disso, a compreensão de que o modo de produção capita-lista tem limites históricos determináveis, e a afirmação daí decorrente do caráter histórico das categorias da economia mercantil, são a chave para o projeto de crítica da economia política.

\section{Substância social, dinheiro e capital}

No desenvolvimento do argumento do Capítulo 1 do Livro I de O Capital, é a análise qualitativa do valor de troca que leva à des-coberta da existência do valor, e daí ao duplo caráter do trabalho produtor de mercadorias e à existência, na economia capitalista, de uma substância do valor, o trabalho abstrato. Por outro lado, o fato de o valor ter uma substância, o trabalho abstrato, permite explicar o dinheiro como sua concretização material, e o capital como esta substância em movimento.

A concepção da mercadoria como constituída de dois contrários - valor de uso e valor -, como resultado de um trabalho que se desdobra em trabalho concreto e trabalho abstrato, reflete teoricamente de maneira bastante adequada a natureza da economia capi-talista. A noção de que a generalização das relações mercantis dá origem a uma substância socialmente constituída, o trabalho abstrato, objetivada como valor das

10 Henryk Grossmann [1975:69-70] chamou a atenção para este ponto.

11 Moishe Postone amplia a importância do duplo caráter do trabalho para a compreensão do caráter histórico da economia capitalista. Fala da existência de uma necessidade histórica, de uma lógica histórica, próprias à economia capitalista, e vincula-as ao duplo caráter das estruturas do capitalismo: "Situando o fundamento material da necessidade histórica, de uma lógica histórica, no 'duplo caráter' das estruturas alienadas caracte-rísticas do capitalismo (a mercadoria como valor e valor de uso, o processo de produção como processo de valorização e processo de trabalho), Marx rompe com qualquer princípio único trans-histórico da história humana.” [Postone 1978, in: Wood III 1988:564] 
mercadorias, base para as comparações entre as diversas mercadorias, é claramente mais realista do que a idéia de uma economia que produz mercadorias de forma generalizada poder ser compreendida como um processo de trocas no qual cada agente procura avaliar qual coleção de bens, dentre as inúmeras possibilidades existentes, lhe daria maior utilidade (representação que constitui o quadro de referência básico da economia neoclássica).

Além disto, da primeira concepção o dinheiro nasce naturalmente, como represen-tação material desta substância social, como figura geral do valor; é uma necessidade teó-rica e prática. ${ }^{12}$ Já para a segunda concepção (neoclássica) a explicação do estatuto do dinheiro torna-se um quebra-cabeça, como é bem conhecido. Assim, comparando os dois quadros teóricos, o da economia de Marx e o neoclássico (sobretudo na sua versão "mais rigorosa", neo-walrasiana), chegamos naturalmente a uma explicação da ori-gem da dificuldade da teoria neoclássica para tratar do dinheiro (e a fortiori do capital): o problema de fundo está em como ela compreende a própria natureza da economia que se propõe a estudar. Em uma palavra, ela desconhece que a marca distintiva da economia capitalista é a produção de mercadorias - unidades (contraditórias) de valor de uso e valor. De fato, volta-se para os bens, entendidos como meros valores de uso, e se ocupa de economias imaginárias.

Para Marx, a economia capitalista é antes de tudo uma economia produtora de mercadorias, e uma característica fundamental da mercadoria é a de ser portadora de va-lor, unidade de valor de uso e valor. O dinheiro, que é o desenvolvimento, a autonomiza-ção, a exteriorização, a materialização da dimensão de valor, está, portanto, presente desde o início.

Outra vantagem importante das categorias de Marx mencionadas é a de abrirem o caminho para uma melhor compreensão do capital como um movimento de valorização e, a partir daí, de toda a dinâmica da economia capitalista. A idéia de um conjunto de relações sociais de interdependência que se reificam no capital como um sujeito automático dominante, cujo objetivo impessoal é a expansão do valor, isto é, da riqueza abstrata, tem mais poder explicativo do que a concepção do capital como insumos utilizados para a produção de bens com o objetivo de maximização de utilidades.

Compreender que a finalidade que move a economia capitalista é a produção de valor, e não de valores de uso, que é a valorização do capital que determina sua dinâmica, é indispensável para a apreensão da natu-

12 Uma economia mercantil exige a constituição de uma representação material geral da riqueza; para que haja producão de mercado-rias, tem de haver dinheiro. O dinheiro concebido desta maneira não é evidentemente nem um simples numerário, nem um simples intermediário das trocas. 
reza do capital e, portanto, do próprio dinheiro - já que poder transformar-se em capital é uma das suas determinações.

\section{Trabalho, valor, improdutividade do capital e mais-}

Quando damos a devida atenção ao duplo caráter do trabalho, podemos compreender outra questão básica (e muitas vezes mal explicada) para a economia de Marx: por que apenas o trabalho humano cria valor. Também aqui é preciso partir da distinção trabalho concreto $x$ trabalho abstrato. O que fundamenta o juízo da "improdutividade do capital" (no sentido de os meios de produção não produzirem valor novo) não é a atribuição de algum 'pri-vilégio' injustificado ao trabalho na produção, ou uma desconsideração da contribuição dos meios de produção (ou da natureza) para a produtividade física ${ }^{13}$; são as características peculi-ares do trabalho na economia mercantil-capitalista. A questão não é, portanto, a im-portância geral do trabalho para a atividade produtiva, e nem mesmo a importância geral do trabalho para a vida em sociedade, mas a sua forma histórica específica. Como diz Isaak Rubin, respondendo aos que questionam a posição "privilegiada" dada ao trabalho na teo-ria do valor-trabalho: “(...) a teoria do valor não trata do trabalho humano enquanto fator técnico de produção, mas da atividade de trabalho das pessoas como a base da vida na so-ciedade e das formas sociais sob as quais este é realizado" [Rubin 1980:97; grifo acrescentado].

Esta questão é freqüentemente mal compreendida, mesmo por bons conhecedores de Marx. Maurice Dobb, por exemplo, em Economía Política y Capitalismo, discute as razões da superioridade da "teoria-custo do valor baseada no trabalho", e diz o seguinte:

\footnotetext{
Por que a teoria-custo do valor baseada no trabalho, que é reconhecidamente apenas um dos fatores de produção da riqueza, haveria de ter uma categoria superior a qualquer outra teoria-custo que se possa imaginar, por exemplo, a que toma o capital ou a terra como a quantidade determinante? (...) Em última análise, esta é, certamente, uma questão prática e não formal. A exatitude de um princípio econômico consiste em que, não obstante fazer abstração de certos aspectos do problema, o faz para centrar a atenção nas características fundamentais desta parte do mundo real à qual se pretende aplicar a teoria.
}

\footnotetext{
13 De fato, Marx enfatizou o oposto, tanto quando chamou a atenção para que o aumento da força produtiva intensifica a produção de valores de uso (como será comentado adiante), como quando, apoiando-se em William Petty, disse que o "trabalho não é a única fonte dos valores de uso que produz, da riqueza material” [O Capital I-I:50-1; El Capital I-I:53].
} 
(...)

(...) Que o trabalho constitui um custo em um sentido único é, naturalmente, um suposto; porém um suposto nascido de um ponto de vista particular acerca do que é a essência do problema econômico. (...) O essencial do problema econômico, de acordo com esta teoria e com a opinião tradicional, consiste na luta do homem com a natureza para arrancar-lhe o sustento segundo as diferentes formas de produção através das diferentes etapas da história. Como disse Petty, o trabalho é o pai e a natureza é a mãe da riqueza. ${ }^{14} \mathrm{O}$ contraste entre a ati-vidade humana (dotada de grande significação como a iniciadora e a geradora da mu-dança e do incremento) e o processo da natureza é fundamental para esta relação. Se quando falamos do problema econômico nos referimos não a seu caráter formal, senão a seu conteúdo real, e tentamos assinalar um elemento comum a diversas formas que a luta econômica adotou nas diferentes etapas da história, é difícil encontrar um princípio que não inclua como elemento fundamental esta relação sempre cambiante entre o trabalho e a na-tureza, e o contraste fundamental entre estes dois fatores. E se tratamos de dar uma expres-são quantitativa a esta relação - o domínio da natureza pelo homem - é difícil achar ou-tra noção simples que não seja o gasto de energias humanas (em um determinado estado da sociedade) como requisito para produzir certo resultado [Dobb 1945:19-20].

Como vemos, Dobb busca o fundamento do vínculo entre trabalho e valor nas propriedades do trabalho comuns às diversas etapas da história, no domínio do gênero humano sobre a natureza. Um pouco adiante, su-gere não haver uma diferença essencial entre a teoria de Marx e a de Ricardo, ao co-mentar que "[o] trabalho concebido objetivamente como o produto da energia humana, era a medida e a essência da 'dificuldade ou facilidade da produção' de que falava Ricardo” [p. 21]. A limitação fundamental de seu argumento é não relacionar o "sentido único" em que o trabalho constitui um "custo" com o duplo caráter do trabalho na economia mercantil-capitalista, e é isto que o leva a buscar justificativas na história humana em geral. ${ }^{15}$

Simon Mohun, que em muitos outros aspectos diverge significativamente das concepções de Dobb, segue no tema da relação entre trabalho e produção de valor um curso semelhante. Propõe a questão: "Por que o valor é tempo de tra-balho, e que espécie de tempo de trabalho é ele?" [Mohun, 1994:214], e responde da seguinte maneira:

[Esta] questão é em alguns aspectos a mais fácil. ${ }^{16} \mathrm{O}$ valor é tempo de trabalho por uma ontologia essencialista na qual o que define a

14 Notemos que Dobb não faz aqui a mesma distinção de Marx entre riqueza material (valor de uso) e riqueza abs-trata (valor), razão pela qual lhe escapa o sentido que Marx dá a esta observação de Petty.

15 Ainda que não se dê conta disso, o trabalho a que Dobb atribui o fundamento do valor é o trabalho concreto.

16 Fica claro que foi uma imprudência de Mohun falar em "questão mais fácil” - para depois errar. 
existência humana como especificamente hu-mana é a atividade produtiva com finalidade. O materialismo histórico de Marx interpretou tal atividade em termos de sua habilidade de transformar o meioambiente no qual se situa, transformação que muda os próprios produtores e portanto muda sua atividade produtiva. Este foco no trabalho humano imediatamente invoca uma teoria do valor trabalho [Mohun 1994:215-6].

Como diz Moishe Postone (referindo-se a Dobb e outros autores; mas o que diz se aplica também a Mohun):

(...) [M]uitos argumentos referentes à análise de Marx da exclusividade [uniqueness] do trabalho como a fonte do valor não se dão conta de sua distinção entre 'riqueza real' (ou 'riqueza material') e valor. A 'teoria do valor-trabalho de Marx', entretanto, não é uma teo-ria das propriedades exclusivas [únicas, unique] do trabalho em geral, mas é uma análise da especificidade histórica do valor como uma forma de riqueza, e do trabalho que suposta-mente o constitui.

[Postone 1993:25-6]

Ou seja, a afirmação de que o "capital" (os meios de produção) é improdutivo não se refere a nenhuma impro-dutividade física dos meios de produção, o que seria absurdo, e foi negado explicitamente por Marx ${ }^{17}$, mas simplesmente da incapacidade de criar valor novo ${ }^{18}$, propriedade que diz respeito ao trabalho abstrato.

A existência da mais-valia vincula-se, portanto, ao duplo caráter do trabalho. Em primeiro lugar, pela criação de valor exclusivamente pelo trabalho humano, no sentido que acabamos de explicitar; em segundo lugar, porque a possibilidade de geração de um excedente depende do duplo caráter da mercadoria força de trabalho, ou seja, da distinção entre o valor de uso da força de traba-lho (o trabalho vivo) e seu valor.

Em terceiro lugar, a existência de um excedente só é possível se o valor criado pelo trabalhador for superior ao valor da sua força de trabalho. Esta condição pode ser garantida a partir da distinção entre produção de valor e produção de valores de uso - que decorre do duplo caráter do trabalho: como o valor da força de trabalho cai quando aumenta a pro-dução de valores de uso, ele pode ser reduzido com o aumento da produtividade física até tornar-se inferior ao valor criado pelo trabalhador. Daí se abre também a possibilidade de produção de mais-valia relativa.

17 Ver nota 13 , acima.

18 Ou seja, o aumento da produtividade reduz o valor unitário das mercadorias; há maior produção de valores de uso sem que aumente o valor produzido por espaço de tempo. 


\section{A interação contraditória trabalho concreto $\mathbf{x}$ trabalho abstrato e a dinâmica da economia capitalista}

Marx conclui a segunda parte do Capítulo I do Livro I, em que amplia o exame do duplo caráter do trabalho representado nas mercadorias, com uma contraposição entre as dinâmicas diver-gentes da produção de valores de uso (de riqueza material) e da produção de valor (de riqueza abstrata), a partir do desenvolvimento da "força produtiva do trabalho" - ou da produtividade do trabalho, termo hoje mais usual. Esta dinâmica decorre do duplo caráter do trabalho:

Força produtiva é sempre, naturalmente, força produtiva de trabalho útil concreto, e deter-mina apenas, de fato, o grau de eficácia de uma atividade produtiva (...); uma mudança de força produtiva não afeta, em si e para si, de modo algum o trabalho representado no valor. Como a força produtiva pertence à forma concreta útil de trabalho, já não pode esta, natu-ralmente, afetar o trabalho, tão logo faça-se abstração de sua forma concreta útil [O Capital I-I:53; El Capital I-I:56-7].

Marx retomou este argumento e o completou no Capítulo V do Livro I, com a explicitação de que a distinção trabalho concreto $\mathrm{x}$ trabalho abstrato leva à duplicação do processo produtivo em processo de tra-balho material e processo de valorização e, portanto, contrapõe a produção de valores de uso, "a atividade produtiva aplicada a um fim", de um lado, à produção de valor, de outro, e no Capítulo XV do Livro I.

Como o valor é medido pelo tempo de trabalho socialmente necessário, a melhora da produtividade reduz a pro-dução de valor por unidade do produto. Há, portanto, uma dinâmica divergente típica da economia capitalista, decorrente da interação contraditória do trabalho concreto e do tra-balho abstrato, da diferença dos seus produtos; o produto do trabalho con-creto (a quantidade física de bens) e o produto do trabalho abstrato (o valor), podem mover-se de modo diferente; o mesmo acontece, portanto, com a produção de riqueza material e de valor. ${ }^{19}$

Dizendo de outra maneira, o que a economia capitalista valoriza (isto é, reconhece como valor) não é a capacidade do trabalho humano, assistido pelos meios de produção e pela técnica, de produzir bens que satisfazem necessidades (ou fantasias) humanas, ou seja, que têm utilidade; é a medida socialmente reconhecida do tempo de trabalho necessário, isto é, do gasto genérico de trabalho humano abstrato.

Certamente a referência de Marx: “(...) a mera análise do trabalho sans phrase, tal como a encontramos em Smith, Ricardo, etc., se choca por

19 Tanto Henryk Grossmann [1975] quanto Moishe Postone [1993] dão a este aspecto um lugar central na sua descrição da dinâmica do capitalismo. 
toda parte fatalmente com pro-blemas inexplicáveis", que está carta a Engels de 08/01/1968 já citada acima, explica-se justamente porque sem a explicitação do duplo caráter do trabalho a dinâmica contraditória que decorre daí não pode ser percebida.

Ter em conta esta interação contraditória é necessário para analisar as motivações dos capitalistas para a introdução de progresso técnico, e as conseqüências que decorrem daí para a dinâmica da economia capitalista. Se o progresso técnico é homogêneo, os empresários capitalistas não têm vantagens enquanto capitalistas com ele (outra coisa são as vantagens que têm enquanto consumidores, que não são seu interesse principal). As vantagens que podem ter enquanto capitalistas vêm da heterogeneidade do progresso técnico, da situação de dianteira em que podem se colocar diante dos concorrentes e, logo, dos ganhos de maisvalia extra que podem ser obtidos a partir da diferença entre valores sociais (ou valores de mercado ${ }^{20}$ ) e valores individuais das mercadorias. Marx trata desta questão brevemente no Capítulo X do Livro I de $O$ Capital, e depois a retoma, de forma mais extensa, ainda que não muito sistemática, no Capítulo X do Livro III.

Dizendo de outra maneira, o progresso técnico, ou seja, a ampliação da capacidade de satisfazer necessidades humanas pela produção (ou de ampliar o consumo de "utilidade" para os indivíduos) não traz uma vantagem direta para os capitalistas (enquanto capitalistas). O progresso técnico só traz vantagens indiretas para um capitalista, se leva a uma desigualdade com outros produtores favorável para ele (ou quando reduz uma desigualdade desfavorável). As vantagens vêm da posição favorável na concorrência, e não da maior eficiência na produção ou da maior capacidade de satisfazer necessidades humanas em si mesmas.

Esta constatação vale também quando analisamos a relação mais geral entre produção e satisfação de necessidades, independentemente do progresso técnico: não há nenhuma vantagem direta para um capitalista na produção de coisas mais úteis. A produção de coisas mais úteis só lhe é vantajosa se estiver associada à sua venda acima do valor (ou do preço de produção), o que pode acontecer se a demanda for maior que a oferta. As vantagens de maior utilidade ou maior produtividade para os capitalistas só podem ser compreendidas a partir de análises dinâmicas de processos de desequilíbrios (que são sempre transitórios, mutáveis; mas situações de desequilíbrios tendem a ser recriadas).

Todas estas questões são decisivas para a compreensão da dinâmica da economia capitalista, bem como para o entendimento de uma razão 
básica pela qual uma "economia de mercado" não pode ser avaliada segundo os critérios da "economia do bem-estar" de corte neoclássico (que é essencialmente uma análise que trata de "bens", e não de "mercadorias", e que usa o método da estática comparativa, isto é, centrado em posições de equilíbrio). Dentro do paradigma neoclássico é muito difícil pensar o impacto contraditório do progresso técnico na economia capitalista.

Por outro lado, é bem conhecido que as motivações dos capitalistas para a busca do progresso técnico dificultam a generalização e ampliação do próprio progresso técnico, embora também o estimulem. Assim, por exemplo, a atribuição de patentes, que garantem por certo tempo a heterogeneidade do progresso técnico e as vantagens dos empresários que as detém (a forma própria da economia capitalista para motivar as empresas a gastarem com pesquisas tecnológicas) resulta numa menor difusão das novas técnicas e num mau aproveitamento dos benefícios do progresso técnico.

A interação contraditória entre trabalho concreto e trabalho abstrato face ao progresso técnico é, portanto, essencial para a compreensão do funcionamento da concorrência entre os capitais e da lei do valor. ${ }^{21}$ Além disso, ela é o ponto de partida necessário para a compreensão de por que o progresso técnico não apenas não é suficiente para evitar as crises, como pode até mesmo provocá-las.

É também o ponto de partida para a tendência ao crescimento da composição orgânica que leva, segundo Marx, à "lei da tendência decrescente da taxa de lucros", vista por ele como lei fundamental do desenvolvimento da economia capitalista. Esta lei representa, em última análise, a forma pela qual se manifesta na economia capitalista a contradição entre o crescimento das forças produtivas e as relações de produção existentes. Aliás, a contraposição entre "forças produtivas" e "relações de produção capitalistas" representa mais um exemplo das dualidades que se desenvolvem a partir do duplo caráter do trabalho.

\section{Aspectos "técnicos" vinculados ao duplo caráter do trabalho}

Finalmente, há diversos aspectos que podemos chamar de "técnicos" (no sentido de aspectos técnicos de análise econômica) que decorrem do duplo caráter do traba-lho, diretamente ou passando pelo duplo caráter da mercadoria. 
1. A distinção "técnica" fundamental entre trabalho e força de traba-lho é um desdobramento do duplo caráter da mercadoria força de trabalho.

2. O duplo caráter do trabalho permite explicar a conservação do valor dos meios de produção pela sua transferência para as mercadorias produzidas (realizada pelo trabalho enquanto trabalho concreto ${ }^{22}$ ) ao mesmo tempo em que é gerado valor novo (pela objetivação de trabalho abstrato).

3. O duplo caráter do trabalho reflete-se, portanto, na distinção entre capital constante (cujo valor é conservado pelo trabalho concreto) e capital variável (que se troca por trabalho vivo e se objetiva como trabalho abstrato).

4. O duplo caráter do trabalho vincula-se, como vimos, à categoria de composição orgâ-nica do capita $^{23}$, que é uma síntese entre a compo-sição técnica (aspecto valor de uso) e a composição em valor (capital constante adiantado/capital variável).

\section{Conclusão}

Podemos considerar que a afirmação de Marx de que o duplo caráter do trabalho é a questão central para a compreensão da Economia Política e para sua crítica é plenamente justificada. Além de estar no centro do caráter histórico específico da economia capitalista, o duplo caráter do trabalho que produz mercadorias fundamenta a dualidade geral das categorias da economia capitalista, e é decisivo para o entendimento do dinheiro, do capital, das bases da produção de mais-valia, das razões da improdutividade do capital e do suposto "privilégio" atribuído por Marx ao trabalho na produção de valor, dos efeitos contraditórios do progresso técnico, da lógica do mercado e, last but not least, de toda a dinâmica contraditória da economia capitalista.

\section{Referências}

BÖHM-BAWERK, Eugen von (1974) [1896]. "La Conclusión del Sistema de Marx”. In: SWEEZY, Paul (1974) (org.), pp. 29-127. Originalmente publicado em alemão.

CARTELIER, Jean (1981) [1976]. Excedente y Reproducción. México, Fondo de Cultura Económica. Edição original francesa.

22 Marx menciona esta questão no Capítulo VI do Livro I. Para constatarmos que "conservar o valor" é proprie-dade do trabalho concreto, basta lembrar que quanto maior for a produtividade, mais valor se conser-vará em cada intervalo de tempo (já que mais meios de produção serão processados). 23 Ponto para o qual Grossmann (1975:71-2) chamou a atenção. 
BORGES NETO, J. Por que o duplo caráter do trabalho é o ...

COLLETTI, Lucio (1974). "Bernstein et le marxisme de la Deuxième Internationale". In: COLLETTI, Lucio. De Rousseau a Lenine. Paris, Gordon \& Breach, pp. 101-174.

DAVIDSON, Paul (1994). Post Keynesian Monetary Theory. Aldershot, Edward Elgar.

DOBB, Maurice (1945) [1937]. Economía Política y Capitalismo. México, Fondo de Cultura Económica. Publicado originalmente em inglês.

ELSON, Diane (ed.) (1979). Value: The Representation of Labour in Capitalism. London, CSE Books.

FAUSTO, Ruy (1983a). Marx - Lógica e Política, Tomo I. São Paulo, Editora Brasiliense.

FAUSTO, Ruy (1983b) [1978]. "Abstração Real e Contradição: sobre o Trabalho Abstrato e o Valor”. In: FAUSTO, Ruy 1983a, pp. 89-138. Artigo publicado originalmente em francês.

GROSSMANN, Henryk (1975) [1940]. Marx, l'Economie Politique Classique et le Problème de la Dynamique. Paris, Editions Champ Libre. Publicação original, em alemão.

KAY, Geoffrey (1979). "Why Labour is the Starting Point of Capital". In: ELSON, Diane (ed.) 1979, pp. 46-66.

MARX, Karl (1975). El Capital. Libro Primero. Volúmenes I, II e III. Buenos Aires, Siglo Veintiuno Argentina Editores.

MARX, Karl (1982a). Para a Crítica da Economia Política. São Paulo, Abril Cultural, Os Economistas.

MARX, Karl (1982b). Notas Marginales al Tratado de Economía Política de Adolph Wagner. México, Ediciones Pasado y Presente.

MARX, Karl (1988). O Capital. São Paulo, Nova Cultural, $3^{\text {a }}$ edição. Cinco volumes: Livro I, Volumes I e II; Livro II, Volume III; Livro III, Volumes IV e V.

MARX, Karl \& ENGELS, Friedrich (1964). Lettres sur "Le Capital". Paris, Éditions Sociales.

MOHUN, Simon (ed.) (1994). Debates in Value Theory. London, Macmillan Press Ltd.

MOHUN, Simon (1994). "Value, Value-Form and Money". In: MOHUN, Simon (ed.) 1994, pp. 214-230.

POSTONE, Moishe (1988) [1978]. "Necessity, Labor, and Time: A Reinterpretation of the Marxian Critique of Capitalism". Social Research, 45 (4), winter 1978, pp. 739-788. In WOOD 1988, pp. 546-577.

POSTONE, Moishe (1993). Time, labor and social domination. New York, Cambridge University Press.

REUTEN, Geert \& WILLIAMS, Michael (1989). Value-Form and the State. London, Routledge.

REUTEN, Geert (1995). “Conceptual Collapses - A Note on Value-Form 
BORGES NETO, J. Por que o duplo caráter do trabalho é o ...

Theory". Review of Radical Political Economics, 27(3):104-110.

ROSDOLSKY, Roman (2001). Gênese e Estrutura de O Capital de Karl Marx. Rio de Janeiro, Contraponto Editora/Editora da UERJ. Originalmente publicado em alemão em 1968.

RUBIN, Isaak Illich (1980) [1928]. A Teoria Marxista do Valor. São Paulo, Brasiliense. Traduzido da $3^{\text {a }}$ edição russa.

RUBIN, Isaak Illich (1994) [1927]. “Abstract Labour and Value in Marx's System”, in MOHUN, Simon (1994), pp. 35-72. Originalmente publicado em russo.

SWEEZY, Paul (org.) (1974) [1949]: Economia Burguesa y Economia Socialista. Buenos Aires, Pasado y Presente, Siglo XXI Argentina Editores. Originalmente publicado em inglês.

WOOD, John Cunningham (ed.) (1988). Marx's Economics: Critical Assessments. Vol. III, Marxian Economic Analysis. London, Croom Helm. 